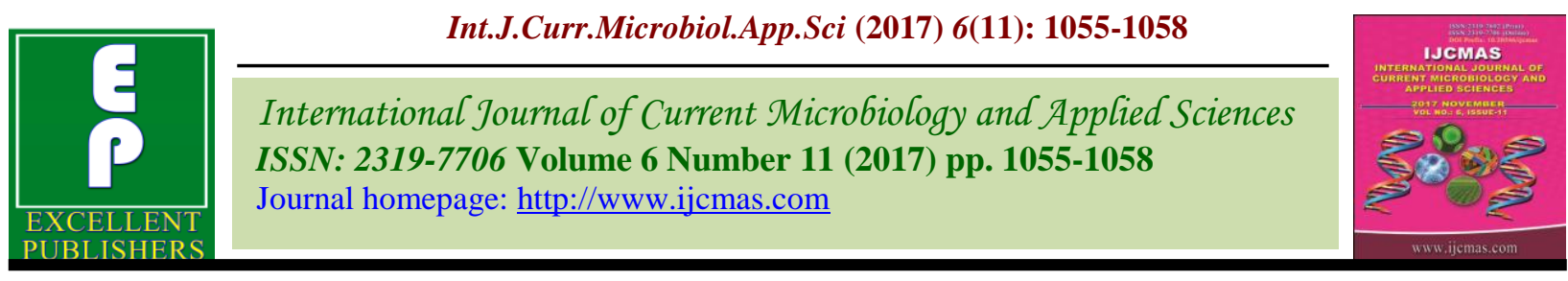

Review Article

https://doi.org/10.20546/ijcmas.2017.611.123

\title{
Role of Trichostatin A as Reprogramming Enhancer on In Vitro Development of Cloned Embryos: A Review
}

\author{
Sajad A. Beigh", Wani A. Ahad, Rumase A. Bhat, Neelofar Nabi, \\ Touqeer Ahmed, Mehrajuddin Reshi and Riaz A. Shah
}

\author{
Faculty of Veterinary Science and Animal Husbandry, Sher-e-Kashmir University of \\ Agricultural Science and Technology of Kashmir, Shuhama, Alusteng, India \\ *Corresponding author
}

\section{A B S T R A C T}

\begin{tabular}{|l|}
\hline Ke y w o r d s \\
HDACi, TSA, \\
SCNT, HMC. \\
\hline Article Info \\
\hline $\begin{array}{l}\text { Accepted: } \\
\text { 10 September } 2017 \\
\text { Available Online: } \\
\text { 10 November } 2017\end{array}$ \\
\hline
\end{tabular}

In cloning during reconstruction of embryo, the oocyte cytoplast reprograms the DNA of a donor nucleus, changing its status from a somatic state to an embryonic state. This remarkable change is due to the unique combination of reprogramming factors (DNAassociating factors) present in the oocyte. The reprogramming factors in the oocyte are not suitably designed to handle the epigenetic status of the somatic cells which often results in an incomplete transition due to inadequate remodelling of the donor nucleus. Recently various reprogramming enhancers have been used either on the developing cloned embryos or on donor cells which check the epigenetic errors by altering histone acetylation levels and increase the developmental competence of cloned embryos. Trichostatin A (TSA), a histone deacetylase inhibitor (HDACi) holding promise for increasing the developmental competence of cloned embryos produced either by somatic cell nuclear transfer (SCNT) or by hand-made cloning (HMC) technique in different species.

\section{Introduction}

Trichostatin A is histone deacetylase inhibitor (HDACi) (Turner, 2000), which is known to be a critical factor for successful reprogramming during SCNT (Armstrong et al., 2006). Histone acetylation decreases the affinity of histone proteins to DNA sequences by neutralizing the positive charge of the histone tails (Hong et al., 1993) which in turn, facilitates transcriptional processes (Horn and Peterson, 2002) because a more extended and open chromosomal structure provides more access to transcriptional regulatory proteins to their target sequences (Vettese-Dadey et al., 1996). Histone acetylation also facilitates better genome imprinting and there by increases the developmental competence of embryos (Turner, 2000). The efficiency of cloning in animals in terms of the birth rates of offspring can be affected by a number of biological and technical factors. However, in cloning, there are inevitably considerable individual differences in the quality of recipient oocytes, donor cells and recipient females, so it is usually very difficult to determine the decisive factors statistically (Ogura et al., 2013). Since cloning process is not very efficient. Only few of transferred embryos routinely develop to full term. This is because the reprogramming factors in the oocyte are not suitably designed to handle the 
epigenetic status of the somatic cells. Therefore, the reprogramming of donor DNA by the oocytes often results in an incomplete transition due to inadequate remodelling of the donor nucleus and may result in errors at epigenetic level (Santos et al., 2003). Several epigenetic remodelling agents have been used to improve the developmental competence of cloned embryos and trichostatin A is most widely studied among them.

\section{Effect of trichostatin A on developmental competence of cloned embryos}

Ianger et al., (2008) studied the effect of trichostatin $\mathrm{A}$, on development and histone acetylation of cloned bovine pre-implantation embryos. The reconstructed SCNT embryos were activated with $50 \mathrm{nM}$ TSA for 13 hours, produced eight-celled embryos with levels of acetylation of histone $\mathrm{H} 4$ at lysine 5 (AcH4K5) similar to fertilized counterparts and was found to be significantly $(\mathrm{p}<0.005)$ greater than that of control NT embryos. Further, TSA treatment resulted in SCNT embryos with pre-implantation developmental potential similar to fertilized counterparts, in terms of cleavage and blastocyst rates or blastocyst total cell number $(\mathrm{p}<0.05)$.

Tsuji et al., (2009) studied the effect of TSA treatment duration on the developmental potential of mouse SCNT oocytes.

To determine the effects of TSA treatment duration, nuclear-transferred (NT) oocytes were cultured for 0 to 26 hours with $100 \mathrm{nM}$ TSA. The SCNT oocytes treated with TSA for 8 to 12 hours had the highest rate of development to blastocysts and full-term foetuses were obtained after treatment for 8 to 12 hours.

When oocytes were treated for 14 hours and 26 hours, blastocyst development rate was significantly decreased and foetuses were not obtained. The findings demonstrated that long-term TSA treatment of SCNT mouse oocytes inhibit the potential to develop into blastocysts and foetuses after transfer.

Beebe et al., (2009) studied the effect of $50 \mathrm{nM}$ TSA on embryo reconstructs for $24 \mathrm{~h}$ after electrical activation resulted in a threefold increase in blastocyst rate (64\%) and also resulted in an increase in the average blastocyst cell number (63\%).

Cervera et al., (2009) studied the effects of the trichostatin A on pre-implantation development, histone acetylation and gene expression pattern of nucleus transferred porcine embryos. Treatment with $5 \mathrm{nM}$ TSA for 26 hours after reconstitution resulted in embryos that reached the blastocyst stage at a higher level (48.1\%) and increased number of cells (105.0) than that of the control embryos in which blastocyst rate were $20.2 \%$ and blastocyst cell number 75.3.

Himaki et al., (2010) studied the effects of trichstatin $\mathrm{A}$ on in vitro development and transgene function in somatic cell nuclear transfer embryos derived from transgenic Clawn miniature pig cells. The SCNT embryos were incubated with or without TSA (50 or $100 \mathrm{nmol} / \mathrm{L}$ ) after activation, cultured in vitro and assessed for cleavage, blastocyst formation and transgene function. The rate of blastocyst formation was found to be significantly $(\mathrm{P}<0.05)$ higher in SCNT embryos treated with $50 \mathrm{nmol} / \mathrm{L}$ TSA than that in control whereas, the rate of cleavage and cell number of blastocyst did not differ.

Cui et al., (2011) studied embryo viability and gene expression of cloned bovine pre-implant embryos in the presence and absence of TSA compared to embryos produced by in vitro fertilization or parthenogenetic activation. The treated embryos were found to be more viable with abated epigenetic errors. 
Kishigami et al., (2006) studied the optimum concentration, timing and period of trichostatin A treatment for cloned mouse embryos were found to be significant. Eventually, this method led to a greater than fivefold increase in the success rate of mouse cloning.

Wang et al., (2011) found significant improvement in the in vitro and full-term development of nuclear transferred (NT) bovine embryos with the trichostatin $\mathrm{A}$.

The epigenetic reprogramming of somatic cell nuclei were studied by comparing the extent of DNA methylation, chromatin structure and development-related genes in in vitro fertilized (IVF) group, NT group, TSA treated NT group single blastocyst using quantitative real-time PCR.

Hu et al., (2012) studied trichstatin A on in vitro development of sheep SCNT embryos. Treatment of cloned sheep embryos with 50nM TSA for 24 hours after activation significantly $(\mathrm{p}<0.05)$ improved blastocyst formation rate $23.3 \%$ compared to control 16.7\%. Moreover, TSA treatment significantly $(\mathrm{p}<0.005)$ increased total cell number per blastocyst $(69.6 \pm 9.7)$ compared with control group (64.1 \pm 8.6$)$. Furthermore, TSA treatment increased expression of the development related genes-OCT4 and SOX2 in SCNT blastocysts.

Jeong et al., (2013) studied the effect of TSA on in vitro development of porcine SCNT embryos and found that TSA treatment (50 $\mathrm{nM}$ ) for 24 hours following oocyte activation improved blastocyst formation rates $(22.0 \%)$ compared with $8.9 \%$ in the non-treatment group. The total cell number of the blastocysts also increased significantly.

Saini et al., (2014) studied the effects of trichostatin A on the buffalo skin fibroblast donor cells and embryos produced by handmade cloning. Treatment of donor cells with TSA $(50 \mathrm{nM})$ resulted in higher in vitro development to the blastocyst stage, reduction of the apoptotic index. Transfer of cloned embryos produced with donor cells treated with TSA led to the birth of a calf that survived for 21 days.

Trichostatin A has been found to exhibit positive effect on developmental competence of cloned embryos in different species when used on donor cells, embryos or both. Not only this but cloned embryos which have been produced using reprogramming enhancers result in low birth defects and increase birth rates when transferred in synchronised animals. Thus using trichostatin A on cloned embryos has a great advantage in future for correcting their epigenetic errors and also on reduction in birth defects that arise due to their untreated transfer in cloning protocols.

\section{References}

Beebe, L. F. S., McIlfatrick, S. J. and Nottle M. B. 2009.Cytochalasin B and trichostatin A treatment post activation improves in vitro development of porcine somatic cell nuclear transfer embryos. Cloning Stem Cells 11: 477-482.

Cervera, R. P., Marti-Gutierrez, N., Escorihuela, E., Moreno, R., and Stojkovic, M. 2009.Trichostatin A affects histone acetylation and gene expression in porcine somatic cell nuclear transfer embryos. Theriogenology 72: 1097-1110.

Cui, X. S., Xu, Y. N., Shen, X. H., Zhang, L. Q., Zhang, J. B., and Kim, N. H. 2011. Trichostatin A modulates apoptotic-related gene expression and improves embryo viability in cloned bovine embryos. Cellular Reprogramming 13: 179-189.

Himaki, T., Yokomine, T., Sato, M., Takao, S., Miyoshi, K. and Yoshida, M. 2010. Effects of trichostatin A on in vitro development and transgene function in somatic cell nuclear transfer embryos derived from 
transgenic Clawn miniature pig cells. Animal Science Journal 81: 558-563.

Hong, L., Schroth, G. P., Matthews, H. R., Yau, P. and Bradbury, E. M. 1993.Studies of the DNA binding properties of histone $\mathrm{H} 4$ amino terminus. Journal of Biological Chemistry 268: 305-314.

Horn, P. J. and Peterson, C. L. 2002.Chromatin higher order folding-wrapping up transcription. Science 297: 1824-1827.

Hu, S., Ni, W., Chen, C., Sai, W., Hazi, W, He, Z., Meng, R. and Guo, J. 2012. Comparison between effects of valproic acid and trichstatin A on in vitro development of sheep somatic cell nuclear transfer embryos. Journal of Animal and Veterinary Advances11 (11):1868-1872.

Ianger, A. E., Ragina, N. P., Ross, P. J., Beyhan, Z., Cunniff, K., Rodriguez, R. M. and Cibelli, J. B. 2008. Trichostatin A improves histone acetylation in bovine somatic cell nuclear transfer early embryos. Cloning Stem Cells 10: 371-380.

Jeong, Y. I., Park, C. H., Kim, H. S., Jeong, Y. W., Lee, J. Y., Park, S. W., Lee, S. Y., Hyun, S. H., Kim, Y. W., Shin, T. and Hwang W. S. 2013. Effects of trichostatinA on In vitro development of porcine embryos derived from somatic cell nuclear transfer. Asian-Australian Journal of Animal Science 26(12): 1680-1688.

Kishigami, S., Mizutani, E., Ohta, H., Hikichi, T., Thuan, N. V., Wakayama.S., Bui, H. T., Wakayama, T. 2006. Significant improvement of mouse cloning technique by treatment with trichostatin A after somatic nuclear transfer. Biochemical Biophysics Research Community 340: 183189.

Ogura, A., Inoue, K., Wakayama, T. 2013. Recent advancements in cloning by somatic cell nuclear transfer. Philosophical Translations of the royal society B368:1609-1612.

Saini, M., Selokar, N. L., Agrawal, H., Singla, S. K., Chauhan, M. S., Manik, R. S. and Palta, P. 2014. Treatment of buffalo (Bubalus bubalis) donor cells with trichostatin A and 5-aza-2'-deoxycytidine alters their growth characteristics, gene expression and epigenetic status and improves the in vitro developmental competence, quality and epigenetic status of cloned embryos. Reproduction, Fertility and Development 101: 236-252.

Santos, F., Zakhartchenko, V., Stojkovic, M., Peters, A., Jenuwein, T., Wolf, E., Reik, W. and Dean W. 2003. Epigenetic marking correlates with developmental potential in cloned bovine pre implantation embryos. Current Biology 13: 1116-1121.

Tsuji, Y., Kato, Y. and Tsunoda, Y. (2009). The developmental potential of mouse somatic cell nuclear-transferred oocytes treated with trichostatin A and 5-aza-2'-deoxycytidine. Zygote 17:109-115.

Turner, B. M. 2000. Histone acetylation and an epigenetic code. Bioessays 22: 836-845.

Vettese-Dadey, M., Grant, P. A., Hebbes, T. R., Crane- Robinson, C., Allis, C.D. and Workman, J.L. 1996. Acetylation of histone H4 plays a primary role in enhancing transcription factor binding to nucleosomal DNA in vitro. EMBO J. 15: 2508-2518.

Wang, Y., Su, J., Wang, L., Xu, W., Quan, F., Liu, J. and Zhang, Y. 2011.The effects of 5Aza-2-deoxycytidine and trichstatin A on gene expression and DNA methylation status in cloned bovine blastocysts. Cellular Reprogramming 13(4): 112-117.

\section{How to cite this article:}

Sajad A. Beigh, Wani A. Ahad, Rumase A. Bhat, Neelofar Nabi, Touqeer Ahmed, Mehrajuddin Reshi and Riaz A. Shah. 2017. Role of Trichostatin A as Reprogramming Enhancer on In Vitro Development of Cloned Embryos: A Review. Int.J.Curr.Microbiol.App.Sci. 6(11): 1055-1058. doi: https://doi.org/10.20546/ijcmas.2017.611.123 